CGG Project \#: 13032

Volume Label: CDVD01340

Archive Date: 2014-November 2

This archive consists of 1 DVD-ROM

\title{
GPR 2014_005_ReadMe.PDF
}

\section{EAST STYX SURVEY AREA:}

Airborne Magnetic, Electromagnetic, and Radiometric Data in Line (Point), Grid, Vector, and Map formats, Talkeetna, Tyonek, McGrath, and Lime Hills quadrangles, south-central Alaska

by

L.E. Burns, CGG, and Fugro Geosciences

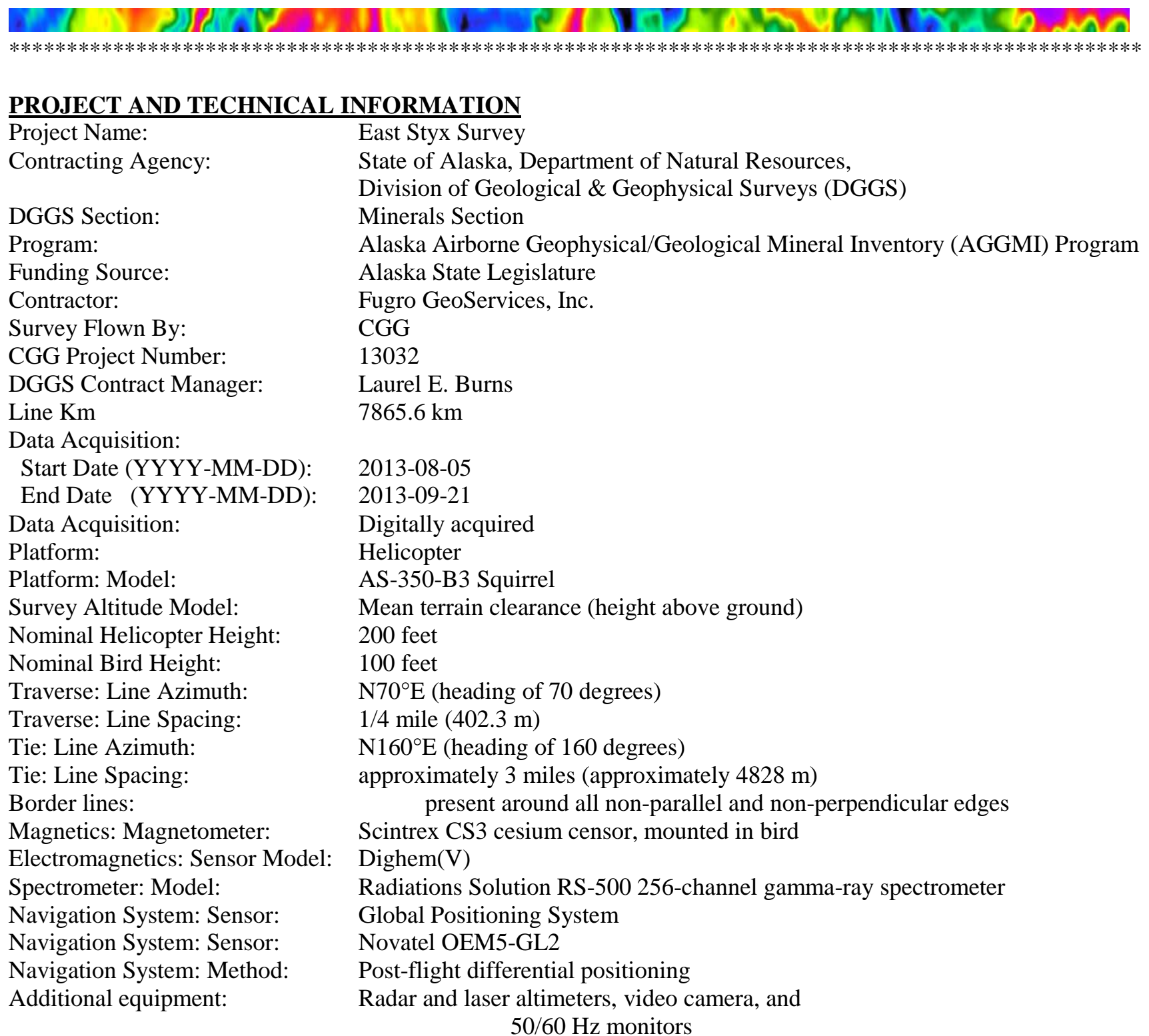




\section{NOTE ABOUT THE PUBLICATION AND FUTURE ADDITIONS TO THE PUBLICATION:}

DGGS is now using '.DOI.' numbers for each given project. For the geophysical surveys, this means all the data for a survey will be associated with that DOI and the original publication number. While the data included in this publication is in its final form, additions at a future date will include CGG's Project Report, interpretation, and EM anomaly picks, stacked-multichannel profiles, and more. These will all be labeled with a gpr2014-5 number, possibly including letter at the end, such as 'A', 'B', 'C', but possibly just added directly onto gpr2014-5. Regardless of the name, the download page will be http://dx.doi.org/10.14509/29142 or through the East Styx Project page (http://www.dggs.alaska.gov/pubs/project-orderform/1227). The project page will have a listing of what is available.

\section{CONTENTS of the PUBLICATION:}

This publication, GPR 2014-5, consists of 1 DVD with files in the root directory and in 7 main folders: metadata, linedata, grids, geotiffs, kmzs, maps, \& vectors. It is also downloadable from the web, in which case the Root Directory files have been placed in the Metadata folder.

\section{ROOT DIRECTORY FILES:}

$\begin{array}{ll}\text { gpr2014_005_readme } & \text { This file; PDF and TXT format. } \\ \text { gpr2014_005_figure1.jpg } & \text { Alaska figure showing location of East Styx survey } \\ \text { gpr2014_005_figure3.jpg } & \text { Detailed figure showing location of East Styx survey map sheets, rivers, and } \\ & \text { 1:63,360-scale quadrangles. }\end{array}$

(Figures 1 and 3 used in from Browse Graphic file.)

\section{METADATA (Folder):}

Metadata is provided in three formats.

$\begin{array}{ll}\text { GPR2014-5.faq.html } & \text { Hypertext Markup Language format (Question and Answer) } \\ \text { GPR2014-5.txt } & \text { ASCII text } \\ \text { GPR2014-5.xml } & \text { Extensible Markup Language format }\end{array}$

\section{LINEDATA (Folder):}

Oasis Montaj (Geosoft) ASCII XYZs have been split into 3 parts due to database size.

\begin{tabular}{ll} 
EastStyx_Linedata.txt & \multicolumn{1}{c}{ Channel list } \\
\hline EastStyx_EM.gdb & Oasis Montaj binary GDB database format for mag \& EM \\
EastStyx_RAD.gdb & Oasis Montaj binary GDB database format for RAD \\
EastStyx_EM_part1XYZ & Oasis Montaj ASCII XYZ format for mag and EM \\
EastStyx_EM_part2XYZ & Oasis Montaj ASCII XYZ format for mag and EM \\
EastStyx_EM_part3XYZ & Oasis Montaj ASCII XYZ format for mag and EM \\
EastStyx_RAD_part1.XYZ & Oasis Montaj ASCII XYZ format for RAD \\
EastStyx_RAD_part2.XYZ & Oasis Montaj ASCII XYZ format for RAD \\
EastStyx_RAD_part3.XYZ & Oasis Montaj ASCII XYZ format for RAD \\
EastSStyx_EM_XYZtoGDB.i0 & Oasis Montaj import template for XYZ file for mag \& \\
EMEastStyx_RAD_XYZtoGDB.i0 & Oasis Montaj import template for XYZ file for RAD
\end{tabular}

OVERVIEW: GRIDS, GEOTIFFS, and GOOGLE EARTH KMZs (3 Separate Folders)

The same data are provided as grids, Geotiffs, and Google Earth KMZs files. The list of the files and the definition is provided below the short sections for the three folders. Gridded files can be manipulated to produce different images. Each Geotiff and KMZ file is just basically one image. For the grids that were made into maps, the corresponding images in the Geotiff and KMZ files are the same image used for the grid in the map. 


\section{GRIDS (Folder)}

All grids are provided in Geosoft binary float and ER Mapper formats. Two files are included for one Geosoft file: the grid file (.GRD) and the projection file (GRD.GI). Three files are provided for ER Mapper data -- a header file (.ERS), a data file (no extension), and the projection file (.ERS.GI).

\section{GEOTIFFS (Folder)}

All file names below have the extension '.TIF' in the GEOTIFF folder. Geotiff files automatically register correctly as NAD 27, UTM Zone 5N in GIS programs. Geotiff files can be opened in any graphics program and as long as the file is not saved, registration information will still be valid.

\section{KMZS (Folder)}

All files in the KMZs folder have the extension '.kmz' (Google Earth zip format). One may drag and drop the KMZ files into 'My Places" in the free downloadable Google Earth program (http://earth.google.com/download-earth.html); data will be automatically registered with the locational information used by Google Earth, i.e. WGS84 datum and CGS projection.

\section{FILES IN THE GRIDS, GEOTIFFS, and KMZS FOLDERS:}

ESt_MagRMI
ESt_MagIGRF
ESt_1VD
ESt_ASig
ESt_TiltDer
ESt_Res56k
ESt_Res7200
ESt_Res900
ESt_TC_cc
ESt_K_cc
ESt_Th_cc
ESt_U_cc
ESt_eTh
ESt_eU
ESt_percentK
ESt_nadr
ESt_ratio_eTh_percentK
ESt_ratio_eU_percentK
ESt_ratio_eU_eTh
ESt_DTM
ESt_AltLasBird

\author{
Residual magnetic intensity (RMI) (nT) - final with IGRF removed \\ Total magnetic field (nT) - final, with IGRF removed \\ First vertical derivative 'dz' ( $\mathrm{nT} / \mathrm{m}$ ) of the RMI \\ Analytic signal (nT/m) calculated from the RMI \\ Tilt derivative (degrees) of the RMI \\ Apparent coplanar resistivity (ohm-m) for 56,000 (56k) Hz. \\ Apparent coplanar resistivity (ohm-m) for $7200 \mathrm{~Hz}$. \\ Apparent coplanar resistivity (ohm-m) for $900 \mathrm{~Hz}$. \\ Corrected total counts (cps) \\ Corrected potassium counts (cps) \\ Corrected thorium counts (cps) \\ Corrected uranium counts (cps) \\ Equivalent thorium (ppm) \\ Equivalent uranium (ppm) \\ Percent potassium (\%) \\ Natural air absorbed dose rate [nGy/h (nanogray per hour)] \\ Equivalent thorium / percent potassium ratio (ppm/\%) \\ Equivalent uranium / percent potassium ratio (ppm/\%) \\ Equivalent uranium / equivalent thorium ratio (unitless) \\ Digital terrain or elevation model (m) \\ EM bird height (m) above surface, measured by laser altimeter in EM bird
}

$* * * * * * * * * * * * * * * * * * * * * * * * * * * * * * * * * * * * * * * * * * * * * * * * * * * * * * * * * * * * * * * * * * * * * * * * * * * * * *$

\section{VECTORS (Folder):}

All data contours provided were made for the maps with this publication. The vectors are provided in ESRI shape file format and Autocad DXF. The files can be opened in variety of geophysical and GIS/CAD software such as Oasis Montaj, MapInfo, ArcGIS, and AutoCAD. 
DATA CONTOURS:

ESt_MagRMI

ESt_ASig

ESt_TiltDer

ESt_Res56k

ESt_Res7200

ESt_Res900

ESt_eTh

ESt_eU

ESt_percentK

ESt_nadr

ESt_ratio_eTh_percentK

ESt_ratio_eU_percentK

ESt_ratio_eU_eTh

\section{OTHER VECTORS:}

ESt_FP

ESt_SecGrid

ESt_UTMGrid
Residual magnetic intensity (RMI) (nT) - final

Analytic signal (nT/m) calculated from the RMI

Tilt derivative (degrees) of the RMI

Apparent coplanar resistivity (ohm*m) for 56,000 (56k) Hz

Apparent coplanar resistivity $(\mathrm{ohm} * \mathrm{~m})$ for $7200 \mathrm{~Hz}$.

Apparent coplanar resistivity (ohm*m) for $900 \mathrm{~Hz}$.

Equivalent thorium (ppm)

Equivalent uranium (ppm)

Percent potassium (\%)

Natural air absorbed dose rate [nGy/h (nanogray per hour)]

Equivalent thorium / percent potassium ratio (ppm/\%)

Equivalent uranium / percent potassium ratio (ppm/\%)

Equivalent uranium / equivalent thorium ratio (unitless)
Flight path

Alaska PLSS Section Grid for the map sheets; includes township and range labels.

Alaska UTM Grid for the map sheets; includes UTM labels on edges

$* * * * * * * * * * * * * * * * * * * * * * * * * * * * * * * * * * * * * * * * * * * * * * * * * * * * * * * * * * * * * * * * * * * * * * * * * * * * * * * * * * * * * * * * * * * * *$

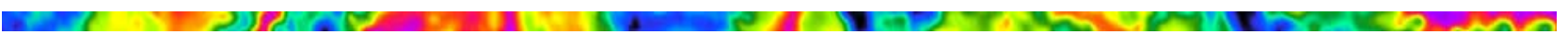

\section{MAPS (Folder)}

Maps are provided as HPGL/2 (PRN) and PDF files. The HPGL/2 files were created with HP Design jet T1300 printer driver and will not work with all plotters, but do plot on the DGGS HP Design Jet T1300. The HPGL/2 files have brighter colors and sharper topography than the Adobe Acrobat files, and should be used or requested if at all possible. Freeware software 'printfile' , available currently at (http://www.lerup.com/printfile) prints HPGL/2 files easily on compatible printers. The Adobe Acrobat format files were created with Adobe Acrobat Distiller v7.0 (PDF 1.5) from postscript files created from the HPGL/2 files.

Three sheets (A,B, and C) are needed to cover the survey area at 1:63,360-scale.

\author{
Zip files include: \\ GPR2014-5_MAPS_1A-7C_asHPGL2.zip \\ GPR2014-5_MAPS_8A-13C_asHPGL2.zip \\ GPR2014-5_MAPS_14A-21C_asHPGL2.zip \\ GPR2014-5_MAPS_22A-29C_asHPGL2.zip \\ GPR2014-5_MAPS_1A-7C_asPDF.zip \\ GPR2014-5_MAPS_8A-13C_asPDF.zip \\ GPR2014-5_MAPS_14A-21C_asPDF.zip \\ GPR2014-5_MAPS_22A-29C_asPDF.zip
}

Map No. GPR2014-5-1 GPR2014-5-2

GPR2014-5-3

GPR2014-5-4

GPR2014-5-5

GPR2014-5-6

GPR2014-5-7

GPR2014-5-8

GPR2014-5-9

GPR2014-5-10

GPR2014-5-11
Grid shown

Residual magnetic intensity (RMI), IGRF removed Residual magnetic intensity (RMI), IGRF removed First vertical derivative of the RMI

Analytic Signal of the RMI

Analytic Signal of the RMI

Tilt Derivative of the RMI

Shadowed RMI

$56 \mathrm{~K} \mathrm{~Hz}$ coplanar apparent resistivity

$56 \mathrm{~K} \mathrm{~Hz}$ coplanar apparent resistivity

$7200 \mathrm{~Hz}$ coplanar apparent resistivity

$7200 \mathrm{~Hz}$ coplanar apparent resistivity
With

topography

magnetic contours

topography

topography

analytic signal contours

topography \& tilt derivative contours

topography \& tilt derivative contours

topography

56K contours

topography

7200 contours 
Map No.

GPR2014-5-12

GPR2014-5-13

GPR2014-5-14

GPR2014-5-15

GPR2014-5-16

GPR2014-5-17

GPR2014-5-18

GPR2014-5-19

GPR2014-5-20

GPR2014-5-21

GPR2014-5-22

GPR2014-5-23

GPR2014-5-24

GPR2014-5-25

GPR2014-5-26

GPR2014-5-27

GPR2014-5-28

GPR2014-5-29
Grid shown

$900 \mathrm{~Hz}$ coplanar apparent resistivity

$900 \mathrm{~Hz}$ coplanar apparent resistivity

Thorium/Potassium (eTh/\%K)

Thorium/Potassium (eTh/\%K)

Uranium/Potassium (eU/\%K)

Uranium/Potassium (eU/\%K)

Uranium/Thorium (eU/eTh)

Uranium/Thorium (eU/eTh)

Potassium (K\%)

Potassium (K\%)

Thorium (eTh)

Thorium (eTh)

Uranium (eU)

Uranium (eU)

Natural air absorbed dose rate (nGy/h)

Natural air absorbed dose rate (nGy/h)

Radioelement-Ternary image

Flight path vector
With (continued)

topography

900 contours

topography

eTh/\%K contours

topography

eU/\%K contours

topography

eU/eTh contours

topography

percent K contours

topography

eTh contours

topography

eU contours

topography

NADR contours

topography

topography

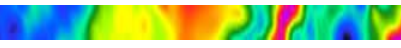

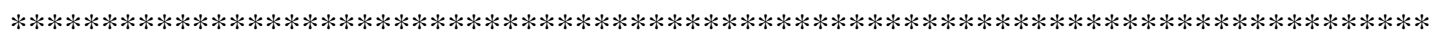

PROJECTION INFORMATION:

GRIDS, GEOTIFFS, VECTORS, \& LINEDATA CHANNELS X_NAD27_z5N and Y_NAD27_z5N

$\begin{array}{ll}\text { DATUM } & \text { NAD27 Spheroid; Clarke } 1866 \\ \text { PROJECTION } & \text { UTM Zone 5N } \\ \text { CENTRAL MERIDIAN } & -153 \\ \text { FALSE EASTING } & 500000 \\ \text { FALSE NORTHING } & 0 \\ \text { SCALE FACTOR } & 0.9996 \\ \text { NORTHERN PARALLEL } & \text { N/A } \\ \text { BASE PARALLEL } & \text { N/A } \\ \text { WGS84 TO LOCAL } & \text { Molodensky conversion method } \\ \text { DELTA X SHIFT } & +5 \\ \text { DELTA Y SHIFT } & -135 \\ \text { DELTA Z SHIFT } & -172\end{array}$

LINEDATA CHANNELS LAT_WGS84 and LONG_WGS84

DATUM

PROJECTION

CENTRAL MERIDIAN

FALSE EASTING

FALSE NORTHING

SCALE FACTOR

NORTHERN PARALLEL

BASE PARALLEL

WGS84 TO LOCAL

DELTA X SHIFT

DELTA Y SHIFT

DELTA Z SHIFT
WGS84

LAT/LON WGS 84

$-153$

500000

0

0.9996

N/A

N/A

Molodensky conversion method

$+0$

$+0$

$+0$

KMZ FILES

DATUM WGS84

PROJECTION Simple Cylindrical / LAT/LON WGS 84 


\section{AVAILABILITY and TECHNICAL REQUIREMENTS:}

ON-LINE: All parts of this publication can be downloaded from the DGGS Web

link http://dx.doi.org/10.14509/29142 in data groups, e.g. MapsAsPDFS. The downloadable groups are near the bottom of the web page.

DVD-ROM: Purchased by mail, e-mail (mailto:dggspubs@alaska.gov), or in person from DGGS, 3354 College Road, Fairbanks, Alaska, 99709-3707 for \$10 plus postage; 1 DVD-ROM.

MAPS: The PDF version of the maps may be viewed, downloaded, or printed individually from the same link as the downloads: http://dx.doi.org/10.14509/29142 or through the East Styx Project page

(http://www.dggs.alaska.gov/pubs/project-orderform/1227) which will contain related geophysical or geological data that are produced in the future. Maps are also available on paper or Mylar through the DGGS office for \$13/sheet plus mail costs.

Please ask for the maps to be printed from HPGL/2 files to ensure the best quality image.

TECHNICAL REQUIREMENTS FOR USE OF THE DATA: Technical requirements for use of all of the data on this publication includes software with ability to use, import, or convert Geosoft float GRD, Geosoft binary GDB or ASCII XYZ files, ESRI Shape files, Adobe Acrobat PDF, Google Earth files, and text files. Free downloadable interfaces to view or convert the gridded and shape files are available at the Geosoft Web site (http://www.geosoft.com; Oasis Montaj viewer). The KMZ files can be dragged and dropped into the 'My Places' folder of the free downloadable 'Google Earth' software. Freeware software 'printfile' (http://www.lerup.com/printfile) prints HPGL/2 files easily on compatible printers. The HPGL/2 files have brighter colors and sharper topography than the PDF maps and should be used for printing when possible. The PDF format maps are the only maps digitally viewable in this publication.

If you have any problems with this archive please contact Laurel Burns or the current geophysicist at the DGGS office. 